\title{
Because She Has a Younger Husband: Critically Examining the Facebookers' Comments Responding to Domestic Violence against a Famous Cambodian Actress
}

\author{
Vannak Dom \\ Graduate School of Sociology, Hallym University, Chuncheon, South Korea \\ Email: vannak.dom@gmail.com
}

How to cite this paper: Dom, V. (2017) Because She Has a Younger Husband: Critically Examining the Facebookers' Comments Responding to Domestic Violence against a Famous Cambodian Actress. Open Access Library Journal, 4: e3932.

https://doi.org/10.4236/oalib.1103932

Received: September 9, 2017

Accepted: October 14, 2017

Published: October 17, 2017

Copyright $\odot 2017$ by author and Open Access Library Inc.

This work is licensed under the Creative

Commons Attribution International

License (CC BY 4.0).

http://creativecommons.org/licenses/by/4.0/

(c) (i) Open Access

\begin{abstract}
This paper is an attempt to explore and understand how SNS users responded to domestic violence against one Cambodian actress. Specially, I examined their comments whether they expressed sympathetic feelings toward her, or blaming her karma/fate, or suggesting divorce. To answer these questions, I used the semantic analysis by debunking socioeconomic backgrounds of the respondents, except gender identity that was identified. This study has found that the majority of men blamed the victim, Karma and the majority of women recommended the victim a divorce and legal assistance, indicating that men still have a strong patriarchal ideology, but women are now more likely to rely on the modern legal system.
\end{abstract}

\section{Subject Areas}

Sociology

\section{Keywords}

Cambodia, Gender, Domestic Violence, Actress, Karma, Divorce

\section{About the Event}

The actress was in her mid $30 \mathrm{~s}$, who has been among the most popular ones in Cambodia. She has one son from her first marriage. The alleged abuser is her second husband, who was reported to be younger than her age, whose occupation was an oriental doctor. According to her statements reported in newspapers, the event happened on April 9, 2017, left her badly injured, yet she already 
forgave him as the man promised not to repeat any more violence. However, the man physically abused her again on April 22, 2017. Cambodian newspapers in Khmer and English languages reported on April 23, 2017. The case went viral on Facebook on April 23, 2017, and become a hot topic for sharing, responding, and talking among SNS users. The incident drew negative reactions and responses from many Cambodians, particularly woman activists.

\section{Introduction}

This study has exploited sociological theories and explained the root causes of violence based on the online users' comments under the article about the domestic violence against the actress that posted on the Facebook page of three famous local Khmer newspapers. By examining only the gender of respondents and analyzing the text, I have debunked the socioeconomic backgrounds of the respondents, such as education, social class, religion, and ethnicity. I went straight forward to examine their opinions responding to the reports using the latent coding method or semantic analysis to analyze each comment [1].

As much as I can argue, violence against women is classical. It is a product of social and cultural heritage which is prevalent regardless of class, culture, religion, or race. Some scholars believed that this "violence is central to the historical development of mankind" [2]. The contemporary global complex society has been more violent than the previous one with the on-going gender violence occurs to women in all forms.

More importantly, instead of improvements in living standards, economic development, education opportunity, peace, etc., the current global study did not give strong evidence showing any improvement or shrinking rate of domestic violence against women in this complex, industrialized and advanced society [3]. Empirically, the latest study indicated the same result that 1 in 3 women experienced physical or sexual abuse at some point in their lives [4]. But taking a look at continent wide, $7 \%-30 \%$ of women in North America experienced physical or sexual abuse, $14 \%$ - 38\% in Latin America and the Carribean, 13\% $46 \%$ in Europe, 6\% - 67\% in Asia, 6\% - 64\% in Africa, and 17\% - 68\% in Oceania [5]. Such high figures showed that society is not a safe place for women [6]. It's necessary for alarming policy makers and activist to rethink the urgent, but effective measures to make the world safe for women.

In Cambodian context, Cambodia is not exceptional like the rest of the world as studies have indicated [7] [8] [9]. Recent surveys conducted by the concerned institutions revealed that the domestic violence rate in Cambodia has not significantly reduced from the last 10 years [8] [10] [11]. The causes and consequences of violence in Cambodia are at rest an endless debate while some blamed social and cultural factors, some blamed economic factors, and some blamed individuals which allow violence against women go unheard and unsolved [12] [13].

\section{Legal Frameworks against Domestic Violence}

On 16 September 2005, the National Assembly passed the law on the prevention 
of domestic violence and the protection of victims (DVL). The Senate approved on 29 September 2005. His Majesty, the King signed the law and put for implementation on 24 October 2005 . This law is firmly aimed at preventing domestic violence, protecting the victims, and strengthening non-violence culture and harmony in Khmer society (article 1). The law is also a response to the constitution, article 38, guaranteed the abolition of the discrimination against women, abolition of the women's labor exploitation, right equality in marriage and family [14].

Four forms of violence: acts harming one's life, acts affecting physical integrity fall under article 3, tortures or cruel acts, and sexual aggression. The article 35 stated that domestic violence is the criminal offences and punished under the penal laws [15].

Both legal frameworks allow Cambodian women to enjoy equal right and safe life, both in public and private space. However, many abusers are still free and some received only minimum prison terms.

According to these legal frameworks, Cambodia does not tolerate any form of violence against women and does not allow any case to be solved outside the court. Any offense shall be subjected to punishments in accordance with the laws. Yet, in 2009, after four years of introduction of domestic violence law, the figure indicated only a minor change in domestic violence rate [11]. Some argued that it is due to law enforcements are still questionable in Cambodia due to limited awareness and understanding of the law among the population and authority [13].

\subsection{Sociological Theories on Domestic Violence}

Since this paper is set to sociologically explore the public response to a famous domestic violence case against one Cambodian actress, therefore, the existing sociological theories help understand the causes and consequences of the problem.

Family Violence Perspectives: family violence from the early 1970s was properly studied to late 1980s, most scholars concentrated on building the theories which could functionally explain the issue, but fail to present empirical literatures on the topic [16] [17]. However, it was Richard Gelles and Murray Straus, who became well known in their 1979 writing on family violence theory [18]. For those who tried to understand domestic violence from family violence perspectives, family violence is inevitable and universal problem exists in most nations and a means of resolving conflicts and disagreements [19]. According to this perspective, domestic violence is inevitable and the victim's sex is not an exception, but ignores who are most likely to become a domestic violence's victim, and also hesitates to identify women as the most-often-victims, and family violence perspectives cease the blame on socio-cultural factors and take the men's sides.

Systems Theory: one of the aspects in systems theory is that every component 
in the social world is a connected dot. Social events systematically occur due to their interactive nature. In this connection, domestic violence is a "common systematic product and almost a universal phenomenon" ([19], p.575). Since systems theorists treat society as a one-system or human body structure-alike, they thought that any change in one social component can trigger a change in others. Social systems function in "complex, interrelated networks of mutual causal elements" ([20], p.18). According to the systematic formulation, domestic violence is ultimately driven by an in-equilibrium relationship of partners "superiority and inferiority" relationship. To therefore re-equilibrate the relationship and reclaim masculine power, husbands are more likely to employ violence means [21] [22]. However, it should be noted that feminists criticized systems theory for being biased against women, for blaming the marital system, and for neglecting social realities [23].

Exchange/Social Control Theory: exchange theory was established during the 1950s, which was germinated by George Humans to study human behaviors and everyday life problem. Violence occurred when individual "husband" expected less punishment or light consequences for his wrong doings [24]. Rooted in criminology, this theory explained the occurrence of the domestic violence as an outcome of an absence of strict social control, inequality in family and society "gender, status..." [20]. Furthermore, "criminals have had ineffective, erratic socialization, and as a result, they lack self-control and therefore commit crimes" ([25], p.161). Hence, the two theories shared the same perspectives on bigger rewards and ineffective social control as a root cause of violent behavior.

Strain Theory/Resource Theory: according to stain and resource theories, root causes such as living in poverty, experiencing early age violence, witnessing a broken family, discrimination, possessing less opportunity, unemployment, environment, friends, communities, culture, depression, anxiety, anger, etc., are believed to make room for domestic violence or crimes [19] [25] [26] [27]. In these views, external social factors as such induce an individual violent means. Strain theory also project that how an individual reacts or protests when he or she experiences being deprived of his/her opportunity.

In resource theory, power is a scare resource. Husband controls and contributes the resource to marriage, family, inheritance right, income, breadwinner status. Some of power components are the ascribed ones. In such a case, husband owns a power resource through skills, accomplishments, culture, and social institutions [28]. Therefore, whenever they feel their power resource and authority are being challenged, they might absorb violent methods to secure or retake the control.

Feminist Theory: feminist theory embraced the women centered perspectives to understand the concept of gender issues. As Feminists argued, gender is a social construction of people to control women and allocate roles [29] so that male supremacy ideology is implemented. Consequently, domestic violence is an expression of patriarchal domination, gender oppression, and control [30]. Feminist theory rules out socioeconomic reasons behind gender violence and lays blame 
upon gender inequality.

On the whole, sociological theories explain domestic violence in the form of how men have taken the control of women's body, sexuality, behavior, decision reinforced by social norms, culture, religion and politics. These theories also have pointed out that as long as women are treated subordinated in society, they will remain vulnerable to violence.

\subsection{Codes for Women and Men}

When one talks about gender issue in Cambodia, he/she tends to lay a blame on social structure, norms, and culture which women are unfairly treated in society although they were considered value holders in society. For instance, ChbabSrei (codes for women) and Chbab Bros (codes for men) which project unequal treatment being as a man and a woman [31]. These two codes were believed to be written in the $14^{\text {th }}$ century by Buddhist monks [32]. The two controversial codes were a part of school curriculum for centuries before they were brought down in 2007 [33] and was applauded by many as it was a good sign of narrowing down the gender bias.

According to both codes, even though it is not widely accepted by many young Cambodians in a modern society, women must be utterly submissive, obedient, and humble to their husbands [32]. Their gender roles are highly anticipated and evaluated by others, especially their husbands. Those who dare to challenge the gender roles, it means they face challenges such as being called as a loose woman and being not a Khmer woman. Such expectations are nothing but positing women secondary to men.

In addition to that, an inferior position of women in family permits society to eventually exclude women from significant benefits and literally subjected to social, cultural, economic and political discriminations. For instance, the Secretary of State of the Ministry of Women's Affairs refused to send women delegate to the Fourth World Conference in Beijing cited that sending inferior (delegate) women would escalate confusion about Cambodia's position in the conference as Cambodian women used to sit at the back row [34]. Meanwhile, the second Prime Minister skeptically voiced his views that he did not agree that men suppress women because his father and himself treat their women well [35]. Their comments reflected how patriarchal ideology deeply rooted in Cambodian society, where women are still subordinate to men.

Although two codes were lifted from the school curriculum, their influences were deeply rooted in Cambodian culture and passed them on to younger generations through socialization process, literatures, cultures, and social norms that should require long term counter measures to deal with its influences.

\section{Literature Review}

There are few academic literatures on the domestic violence issue in Cambodia [9] [36] [37]. But, there are reports and indications of the issues occasionally 
collected and published by the NGOs and government for policies [8]. These surveys and reports are fundamentally serving those who want to understand how domestic violence is viewed from women's perspectives, responses, and perceptions and also of those in a policy level.

Although laws, policy and actions have been adopted against the domestic violence, the law enforcements are ineffective enough to crack down on the issue and many cases remain unheard. One part is an old Khmer say "Do not bring fire out of home" which keeps reminding women to keep silent and endure the suffering. Furthermore, police and victims are not sure to treat it as a legal problem or family problem. Meanwhile, some experts lay blames police ignorance and culture in the matter [13]. These resulted in many criminal cases were settled outside the court.

Because cultural and social structures locate women in a subordinated position and society gives high value on virginity, Cambodian women become the victims of violence or are more likely to suffer even during their second marriage. The analysis [37] using the 2005 demographic and health survey has revealed that $20 \%$ of remarried women experienced emotional violence and $14 \%$ experienced physical violence. These women were more likely to experience emotional and physical violence in their second marriage [37].

This phenomena reflect that domestic violence is one of the serious social problems occurred due to male supremacy ideology placing women in an inferior position. Many victims of domestic violence accepted the physical and emotional abuses by justifying it from social and cultural biases. For instance, study in Pakistan found that a majority of women remained silent because they think they are weak, and out of respect for husbands and the elderly in the family [38]. Another survey study in 25 low and middle income countries indicated wives believed that domestic violence against women was appropriate and necessary in some circumstances [39]. Such justification does not only allow domestic violence against women to occur, but also on children, which teach them to absurd violence as a mean to have the upper hand on any decision in life. Some scholars contended that lack of cultural competence as a main reason concerning the issue [40] [41].

Similarly, the National Institute of Statistics/Ministry of Planning of Cambodia had conducted a demographic survey in 2014 and published in 2015 found that 1 in 5 Cambodian women aged 15 - 64 were reported to experience physical or sexual violence by their partners. The same survey highlighted that women believed that a man can be justified under circumstances, such as disrespect, refusing sex, asking out his affairs, being unfaithful not taking care of children [42]. Many Cambodian women tend to think domestic violence as a normal problem by comparing a tongue and teeth which always have a clash.

Furthermore, besides justifying the domestic violence, many of them blamed their Karma and redemption. Such belief, of course, will maintain family bond, but women live miserably and the abusers walk free instead of receiving any punishment. According to the study conducted among migrant women in the US 
found that Cambodian women tried to endure the violence by thinking they repay the Karma from previous lives [35]. Therefore, laying the blame on Karma would jeopardize the justice [42]. I argue that although religious belief constitutes the social bond, social integration and many more, belief in Karma in the context of violence does not only solve the problem, but also make the problem worse.

\section{Method}

\subsection{Data Collection}

The sample of the research is constituted from responding comments within 24 hours, taking from the time when the each news outlet posted on Facebook. These news outlets were among the most popular newspapers in Cambodia, having at least 500,000 subscriptions. The comments were recorded using iPad to screenshot in the form of photos. The screenshot comments were printed afterward for the purpose of identifying the gender of the respondents and doing the latent coding on the comments.

The three newspapers which were chosen here are the Khmer medium newspapers available in printing and digital forms. These three news outlets are Koh Santepheap Daily, Kampuchea Thmey Daily, and Voice of Democracy. During the process of collecting the responding comments, number of shares of the article, number of views of the article in the main website and number of subscribers were recorded. Table 1 was also made to present the audience shares of each newspaper by the time of study.

\subsection{Coding Procedure}

To identify the gender of respondents, I identified the gender of identity using the most common female names and male names in Cambodia $(1=$ male, $2=$ female).

The responding comments with sticker icons such as smiley, sad, angry, etc. were eliminated from coding. After the elimination, there were 395 responding comments applicable for coding how they responded to the case, and out of which $46.1 \%$ were men $(n=182), 53.9 \%$ were women $(n=213)$. In the coding process, one Cambodian student was asked to identify the gender of respondents based on familiar Khmer names and compared with researcher afterward. The

Table 1. News outlets.

\begin{tabular}{ccccc}
\hline Name & $\begin{array}{c}\text { Number of shares } \\
\text { of the article }\end{array}$ & $\begin{array}{c}\text { Number of } \\
\text { viewers on } \\
\text { website }\end{array}$ & $\begin{array}{c}\text { Number of subscribers } \\
\text { of each news outlet } \\
\text { (time of study) }\end{array}$ \\
\hline $1 \quad$ & Koh Santepheap Daily & 2665 shares & 9436 & $2,861,754$ \\
2 & Kampuchea Thmey Daily & 917 shares & 5768 & $1,965,879$ \\
3 & $\begin{array}{c}\text { Voice of Democracy } \\
\text { (VODHOTNEWS) }\end{array}$ & 765 shares & 9447 & 583,972 \\
\hline
\end{tabular}


disagreement was $5 \%$ and later was resolved. The student received a reward for his labor.

\subsection{Variables and Data Analysis}

To categorize the responding comments, the each comment was coded into two separate variables: first response and second response. The first response included " 1 = recommending for a divorce or legal actions, 2 = expressing sympathy, 3 = blaming her, 4 = blaming her karma, $5=$ using abusive words and stereotypes on the man's look, 6 = others". The second variable has the same value. However, the second group of variable was eliminated after coding since there were only 36 responding comments were applicable for the coding. To code the comment, only the first central idea of the comment (first sentence) was coded. In case there are two or more sentences were expressed, it is only the first sentence was coded.

After grouping the comments, data were entered into SPSS to perform simple cross-tabulation analysis between the independent variable and dependent variables.

\section{Findings}

The total respondents were 395 people (women, $=213$, "53.9\%" and men, $\mathrm{N}=$ 182 , "46.1\%") who responded to the news article from all three news outlets (Table 2).

The study found that a majority of women $(20 \%)$ and $(10 \%)$ of men suggested that the victim get a divorce and seek legal assistance. A majority of men (14\%) and $(9 \%)$ of women blamed the victim. The study also revealed that women (7\%) expressed their sympathetic feelings against (4\%) of men. It further revealed that there were more women (9\%) than men (8\%) had stereotypes on the man's look, career, and backgrounds.

Table 2. Gender and responding comments of respondents.

\begin{tabular}{|c|c|c|c|c|}
\hline \multirow{2}{*}{ Perception } & & \multicolumn{2}{|c|}{ Gender } & \multirow{2}{*}{ Total } \\
\hline & & Male & Female & \\
\hline \multirow{2}{*}{$\begin{array}{l}\text { Recommending a divorce } \\
\text { or legal assistance }\end{array}$} & $\%$ within perception & $33 \%$ & $67 \%$ & $100 \%$ \\
\hline & $\%$ of total & $10 \%$ & $20 \%$ & $30 \%$ \\
\hline \multirow{2}{*}{ Expressing sympathy } & $\%$ within perception & $33 \%$ & $67 \%$ & $100 \%$ \\
\hline & $\%$ of total & $4 \%$ & $7 \%$ & $11 \%$ \\
\hline \multirow{2}{*}{ Blaming her faults } & $\%$ within perception & $61 \%$ & $39 \%$ & $100 \%$ \\
\hline & $\%$ of total & $14 \%$ & $9 \%$ & $23 \%$ \\
\hline \multirow{2}{*}{ Blaming her karma/fate } & $\%$ within perception & $36 \%$ & $64 \%$ & $100 \%$ \\
\hline & $\%$ of total & $3 \%$ & $6 \%$ & $9 \%$ \\
\hline \multirow{2}{*}{$\begin{array}{l}\text { Stereotypes on the man's looks, } \\
\text { career, and backgrounds }\end{array}$} & $\%$ within perception & $46 \%$ & $54 \%$ & $100 \%$ \\
\hline & $\%$ of total & $8 \%$ & $9 \%$ & $17 \%$ \\
\hline \multirow{2}{*}{ Others } & $\%$ within perception & $76 \%$ & $24 \%$ & $100 \%$ \\
\hline & $\%$ of total & $7 \%$ & $2 \%$ & $9 \%$ \\
\hline Total & $\%$ of total & $46 \%$ & $54 \%$ & $100 \%$ \\
\hline
\end{tabular}


The findings suggested that women become aware that domestic violence is a crime, which women should not endure according to Karma, but should immediately seek a legal assistance. However, in this study still presented how strong the patriarchal ideology which have deep-rooted in men's mentality as indicated that a majority of men blamed the victim.

\section{Discussions}

This study has revealed one positive group of comments from women (20\%) regarding their suggestions for legal actions against the abuser and suggested the victim get separated from her abuser, which was higher than the demographic study in $4.7 \%$ [11]. These findings reflected a better understanding of women regarding justice provided by laws. Since Cambodia has sufficient laws to tackle domestic violence, family, especially women should seek legal helps from police or authority according to laws and policies made by government to prevent violence against women [43]. These findings could be a positive one which the concerned entities have expected from laws and campaigns and can be best explained by the exchange theory as it views that the lesser consequence of crime motivates high crime rate [20]. Therefore, I argue that when there are more women considered domestic violence a legal offense and seek legal assistance, this will alert men to reconsider twice before abusing their women.

However, blaming the victim has still a prominent perception among responding comments as the study found most men blamed the woman and shown little sympathy for the victim. Moreover, the number of female respondents blamed the victim was the second highest responding comments. Furthermore, second highest number of women also blamed the victims. These findings revealed that patriarchal ideology still tightly controls Cambodian society. Both men and women still think violence can be justified because women should respect men [36] [38] [39]. The women were silent because they were afraid to break the social norms [44] [45]. Such belief has not changed as the findings revealed, indicated that women are vulnerable to violence and subjected to discrimination both in the family and society, and can motivate children to absorb violence to solve their problem [46]. From family violence perspectives and feminist theory, the findings highlight that patriarchal domination is strong in Cambodia and respondents do not consider domestic violence a serious crime.

Regarding the perception on fate and Karma, the findings illustrated that such belief is also still prominent among Cambodians, especially women (6\%). As many people believed that the person should endure the suffering according previous life's Karma [43] [47]; others might intentionally exploit this belief to achieve their goals and placed women in inferior positions [48]. Belief in Karma in the context of violence/crime can jeopardize justice, perpetuate inequality, and encourage more violence as the criminal receives rewards from violence rather than get punished as explained in the exchange/social control theory. 


\section{Conclusion}

On the whole, this paper does not try to generalize the findings although there were similar findings in other studies. However, these findings reveal a current change in perception of men and women regarding domestic violence, which show some positive influences of laws where women suggested legal actions or divorce rather than blamed Karma or treated it as a family matter. Significantly, it projected that legal awareness among Cambodian women is improving. Thus, I think that Cambodia should bring the best out of awareness campaigns for better results in the future. Academically, although this study is a small study which has not looked at socioeconomic backgrounds of respondents to predict its relationship with their perceptions, it can definitely constitute an example for the future study to understand this issue in a deeper and more scientific analysis. I also expect that this study will add to the existing literature on the domestic violence, especially in Cambodian case.

\section{References}

[1] Neuman, W. (2014) Social Research Methods: Qualitative and Quantitative Approaches. Pearson, Essex, UK.

[2] Keeling, J.J. and Mason, T. (2008) Domestic Violence: A Multi-Professional Approach for Healthcare Practitioners. Open University Press, Maidenhead.

[3] UNSD (2015) Violence against Women Is Everywhere. https://unstats.un.org/unsd/gender/downloads/Ch6_VaW_info.pdf

[4] WHO (2016) Violence against Women. http://www.who.int/mediacentre/factsheets/fs239/en/

[5] International Center for the Prevention of Crime (2014) Study on Intimate Partner Violence against Women Government of Norway. International Center for the Prevention of Crime, Montreal, Canada.

[6] Semahegn, A. and Mengistie, B. (2015) Domestic Violence against Women and Associate Factors in Ethiopia; Systematic Review. Reproductive Health, 12, 1-12. https://doi.org/10.1186/s12978-015-0072-1

[7] CAMBOW (2007) Violence against Women: How Cambodian Laws Discriminate against Women. LICHADO, Phnom Penh, Cambodia.

[8] CAMBOW (2002) CAMBOW Objects to Provisions in the domestic violence draft law. http://www.licadho-cambodia.org/pressrelease.php?perm $=38$

[9] Yount, K. and Carrera, J. (2006) Domestic Violence against Married Women in Cambodia. Social Forces, 85, 355-387.

[10] Ministry of Women's Affairs $(2008,2014)$ First, and Second National Action Plan to Prevent Violence against Women (2008-2012). Ministry of Women's Affairs, Phnom Penh.

[11] Neary Ratanak (2009) Violence against Women: 2009 Follow up Survey. Neary Ratanak, Phnom Penh.

[12] Salva, A. (2016) Domestic Violence in Cambodia http://thediplomat.com/2016/04/domestic-violence-in-cambodia/

[13] Kohlbacher, S. and Buth, K. (2016) Police Ignorance, Culture Hinder Progress on Domestic Abuse. 
https://www.cambodiadaily.com/news/police-ignorance-culture-hinder-progress-d omestic-abuse-115007/

[14] National Assembly of Cambodia $(1993,1998,2006)$ The Constitution of the Kingdom of Cambodia. Phnom Penh.

[15] National Assembly of Cambodia (2005) Law on Prevention of Domestic Violence and the Protection of Victims. Phnom Penh.

[16] Hyde-Nolan, M.E. and Juliao, T. (2012) Theoretical Basis for Family Violence. In: Fife, R.S. and Scharger, S., Eds., Family Violence: What Health Care Providers Need to Know, Jones \& Bartlett Learning, Ontario, 5-16.

[17] Ohlin, L. and Tonry, M. (1989) Family Violence in Perspective. Crime and Justice, 11, 1018. https://doi.org/10.1086/449150

[18] Gelles, R.J. and Straus, M.A. (1979) Determinants of Violence in the Family: Toward a Theoretical Integration. In: Burr, W.R., Hill, R., Nye, F.I. and R.I.L., Eds., Contemporary Theories about the Family, Free Press, New York, 550-581.

[19] Lawson, J. (2012) Sociological Theories of Intimate Partner Violence. Journal of Human Behavior in the Social Environment, 22, 572-590. https://doi.org/10.1080/10911359.2011.598748

[20] Giles-Sims, J. (1983) Wife Battering: A Systems Theory Approach. Guilford Press, New York.

[21] Hoffman, L. (1981) Foundations of Family Therapy. Basic Books, New York.

[22] Weitzman, J. and Dreen, K. (1982) Wife Beating: A View of the Marital Dyad. Soc. Casewk, 63, 259-265.

[23] Bograd, M. (1984) Family Systems Approaches to Wife Battering: A Feminist Critique. American Journal of Orthopsychiatry, 54, 558-568. https://doi.org/10.1111/j.1939-0025.1984.tb01526.x

[24] Molm, L.D. (2005) George Homans. In: George, R., Ed., Encyclopedia of Social Theory, Sage Publications, Vol. 1, 381-385. https://doi.org/10.4135/9781412952552.n145

[25] Best, J. (2005) Crime. In: Ritzer, G., Ed., Encylopedia of Social Theory, Sage Publications, 161-163.

[26] Gibson, C.L., Swatt, M.L. and Jolicoeur, J.R. (2001) Assessing the Generality of General Strain Theory: The Relationship among Occupational Stress Experienced by Male Police Officers and Domestic Forms of Violence. Journal of Crime and Justice, 24, 29-57. https://doi.org/10.1080/0735648X.2001.9721133

[27] Goode, W.J. (1971) Force and Violence in the Family. Journal of Marriage and Family, 33, 624-636. https://doi.org/10.2307/349435

[28] Bersani, C.A. and Chen, H.-T. (1988) Sociological Perspectives in Family Violence. In: Van Hasselt, V.V., Morrison, R.L., Bellack, A.S. and Hersen, M., Eds., Handbook of Family Violence, Springer Science, New York, 57-88. https://doi.org/10.1007/978-1-4757-5360-8_4

[29] Ritzer, G. (2010) Sociological Theory. McGraw-Hill, New York.

[30] Dobash, R. and Dobash, R. (1980) Violence against Wives: A Case against the Patriarchy. Open Books, London.

[31] Mouen, M. (1957) Codes for Men and Women. Khmer Version, Tech Hong Library, Phnom Penh.

[32] Hoefinger, H. (2013) Sex, Love and Money in Cambodia: Professional Girlfriends and Transactional Relationship. Routledge, New York. 
[33] Grace, K. and Eng, S. (2015) There Is No Place for "Chbab Srey" in Cambodia Schools.

https://www.cambodiadaily.com/opinion/\%C2\%ADthere-is-no-place-for-chbab-sre y-in-cambodian-schools-85230/

[34] Heng, S. (1995) Man to Lead Women to Beijing... of Course. http://www.phnompenhpost.com/national/man-lead-women-beijing-course

[35] Heng, S. (1995) Hun Sen Says Change Liberal Women's Law. http://www.phnompenhpost.com/national/hun-sen-says-change-liberal-womens-law

[36] Bhuyan, R., Mell, M., Senturia, K., Sullivan, M. and Shiu-Thornton, S. (2005) Women Must Endure According to Their Karma: Cambodian Immigrant Women Talk about Domestic Violence. Journal of Interpersonal Violence, 20, 902-921. https://doi.org/10.1177/0886260505277675

[37] Eng, S., Szmodis, W. and Grace, K. (2017) Cambodian Remarried Women Were at Risk for Domestic Violence. Journal of Interpersonal Violence, 1-26.

[38] Madhni, F.I., Karmaliani, R., Patel, C., Bann, C.M., Mcclure, E.M., Pasha, O., et al. (2015) Women's Perceptions and Experiences of Domestic Violence: An Observational Study from Hyderabad Pakistan. Journal of Interpersonal Violence, 1-25.

[39] Landsford, J.E., Deater-Deckard, K., Bomstein, M.H., Putnick, D.L. and Bradley, R.H. (2013) Attitudes Justifying Domestic Violence Predict Endorsement of Corporal Punishment and Physical and Psychological Aggression towards Children: A Study in 25 Low- and Middle-Income Countries. The Journal of Pediatric, 1208-1213.

[40] Bent-Goodley, T.B. (2004) Perceptions of Domestic Violence. Health \& Social Works, 29, 307-316. https://doi.org/10.1093/hsw/29.4.307

[41] Rorie, J.-A.L., Paine, L.L. and Barger, M.K. (1996) Primary Care for Women: Cultural Competence in Primary Care Services. Journal of Nurse-Midwifery, 41, 92-100.

[42] National Institute of Statistics/Ministry of Planning (2015) National Survey on Women's Health and Life Experiences in Cambodia. National Institute of Statistics/Ministry of Planning, Phnom Penh.

[43] Cox, J.L. (1989) Karma and Redemption: A Religious Approach to Family Violence. Journal of Religion and Health, 28, 16-25. https://doi.org/10.1007/BF00987500

[44] Ministry of Women's Affairs (2010) National Survey on Women's Health and Life Experience in Cambodia. Ministry of Women's Affairs, Phnom Penh, Cambodia.

[45] Eng, S., Li, Y., Muslow, M. and Fischer, J. (2010) Domestic Violence against Women in Cambodia: Husband's Control, Frequency of Spousal Discussion, and Domestic Violence Reported by Cambodian Women. Journal of Family Violence, 237-246. https://doi.org/10.1007/s10896-009-9287-7

[46] Chua, J. (2017) Cambodia's Cycle of Abuse. http://www.phnompenhpost.com/national/cambodias-cycle-abuse

[47] Dhar, R.L. (2014) Domestic Violence in Rural India: Phenomenological Study from Cultural Perspective. Marriage \& Family Review, 50, 533-559. https://doi.org/10.1080/01494929.2014.915281

[48] Purkayastha, B. (2000) Liminal Lives: South Asian Youth and Domestic Violence. Journal of Social Distress and the Homeless, 9, 201-219. https://doi.org/10.1023/A:1009408018107 
Submit or recommend next manuscript to OALib Journal and we will provide best service for you:

- Publication frequency: Monthly

- 9 subject areas of science, technology and medicine

- Fair and rigorous peer-review system

- Fast publication process

- Article promotion in various social networking sites (LinkedIn, Facebook, Twitter, etc.)

- Maximum dissemination of your research work

Submit Your Paper Online: Click Here to Submit

Or Contact service@oalib.com 